\title{
7. Television and environmental sustainability: Arguing a case for a code of standards in NZ
}

\section{ABSTRACI}

This article explores the portrayal of the environment and environmental sustainability by free-to-air network television in New Zealand. The results are based on a three-month survey of a) the portrayal of the use and treatment of the environment, and b) the reporting of environmental news. While television includes environmentally-oriented programmes (eg. some $\mathrm{BBC}$ Horizon documentaries), there are no regular programmes about the state of the environment, sustainable use of resources and energy, and there is no regular environmental slot in the news in New Zealand. Some programmes and advertisements are environmentally unfriendly and a few trivialise resource abuse. It is argued that the media has an 'orchestrational' influence on social norms and behaviours, and that to eliminate countermessages requires the addition of a new 'environmental standard' to the Code of Broadcasting Practice. It is also argued that coverage of environmental news is quite narrow and, in the case of Television New Zealand, inconsistent with the stated aims of the Television Charter. New Zealand television could and should make a valuable contribution to environmental sustainability.

IAN S. SPELLERBERG and GRAEME D. BUCHAN

Lincoln University, Christchurch

NICK EARLY

Restore NZ Ltd, Christchurch

USTAINABLE development has economic, social, cultural and environmental dimensions. Indeed, some would argue that of all these, environmental dimensions are the most important. There is an environ- 
mental imperative (UN, 2005) and environmental issues, both natural and human-induced, are pervasive. Thousands of organisations deal with environmental issues and their solutions. Every person on earth is affected by some of these issues and there is a growing interest in the health of the environment. That growing interest is evident in New Zealand (Hughey et al., 2004). If environmental issues do pervade every aspect of our lives, then we would expect that reports of such issues $n$ them would feature regularly in the media - in newspapers, periodicals, radio and television. Within the mass media, television has a particularly influential role because of its immediacy and visual impact. However, there appears to be relatively little research on the environmental or nature content of television programmes. An exception is the work by Shanahan and McComas $(1997,1999)$, who analysed network television programmes in Boston, Massachusetts, and Ithaca, New York, in the early 1990s. Chapman et al. (1997) include some aspects of the way and the extent to which environmental issues are portrayed in newspapers, on the radio and on television.

The aim of our research was to undertake a preliminary investigation into how the environment is portrayed, and the extent to which environmental issues are reported, on NZ national free-to-air network television in New Zealand. The project had three components :

1. Estimation of the proportion of time devoted to environmental programmes. (Here, 'programmes' are all broadcasts excluding news and advertisements).

2. Estimation of the extent to which environmental issues were reported on prime-time national television news.

3. Assessment of the manner in which the environment was portrayed in advertisements.

It was predicted that the amount of time devoted to 'environmental' material would be small, but would be at least a few hours each week.

\section{Programmes}

Programmes on TV1, TV2 and TV3 were logged over a three-month period from November 2004 to the end of January 2005. The survey was based on 'sample' periodical viewing of the listed programmes. An initial three weeks was spent devising a method for assessment, including the assessment of what could be interpreted as being 'environmental' or 'not environmental' 
(see Table 1). This was a subjective classification. The 'environmental programmes' were considered to be those that contained elements of environmental sustainability and which had environmental sustainability outcomes. Programmes that were considered to be not 'environmental' were those that appeared to have material which could be considered contrary to good environmental practice.

\section{Table 1: TV programmes considered to be 'environmental'}

\begin{tabular}{|l|l|}
\hline 'Environmental' & Not 'environmental' \\
\hline $\begin{array}{l}\text { Programmes on Antarctica } \\
\text { 'Earth reports' }\end{array}$ & $\begin{array}{l}\text { House makeover or garden } \\
\text { makeover programmes } \\
\text { Gardening programmes }\end{array}$ \\
Some 'Grassroots' programmes & DIY programmes \\
'Harnessing nature' & Renovation programmes \\
'Wild New World' & \\
Some space exploration programmes & \\
Some Michael Palin programmes & \\
Some 'Zoo' programmes. & \\
\hline
\end{tabular}

\section{Results}

The total amount of programme time was 2200 hours per channel (a total of $6600 \mathrm{hrs}$ ). The percentages of total broadcasting time devoted to environmental programmes are shown in Figure 1. The Earth Report programme probably best fitted the definition of 'environmental', but was broadcast at 4.30am, as were some programmes on Antarctica. News items (covered in more detail below) occasionally included 'environmental' reports, but these were presented as environmental disasters or crises and often focused on issues with visual impact. A recurrent aspect was environmental or animal reports at the end of the News - typically presented emotionally as the 'cuddly' animal, or the animal-human interaction.

\section{Discussion}

The proportion of time devoted to environmental material was disappointing. Most material fitted the 'popular magazine' image. It was entertainment, not informative and often not serious. Some authors have drawn attention to the fact that environmental issues are sometimes sensationalised (see for example Gorney, 1992). In the US, research by Shanahan and McComas (1997, 


\section{Figure 1: Percentage of time on 'environmental' programmes}

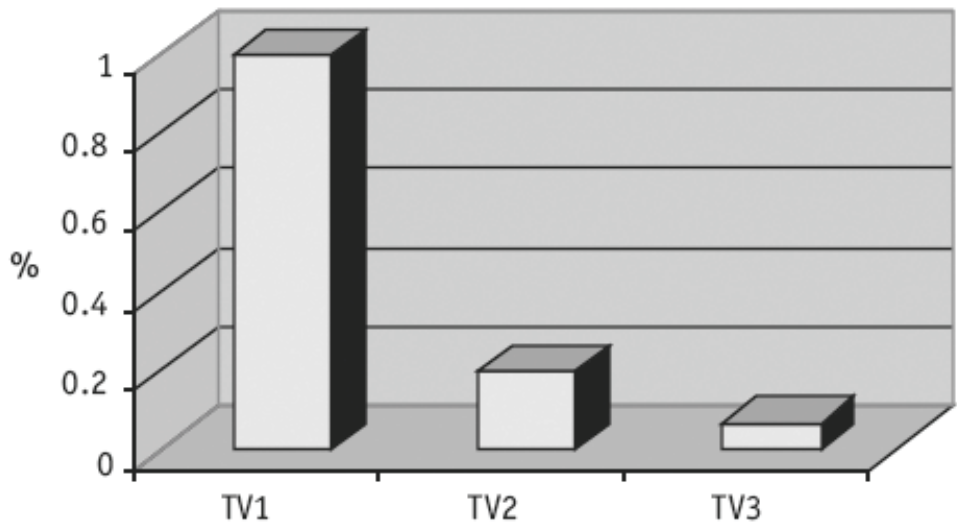

1999) showed that environmental and nature themes are covered less frequently than themes such as family, homes, relationships and money. They also found that attention to environmental issues decreased from 1991 to 1995.

Not for the first time has the question been asked, why are the environment and environmental issues not given more time on television? This question has, for example, been addressed by several authors, including Chapman et al. (1997), Musukuma (2002) and Sims (2002), and in two anonymous editorials in the journal Intermedia (Anonymous, 2003a, 2003b). Some of the reasons include the complexity of the issues and the lack of total agreement between environmental experts. We would argue that there is no less complexity and no less disagreement between experts in economics or social issues. One other reason is the slow rate of environmental change. It has been suggested, for example, that journalists struggle to find something newsworthy in an area where there is so little change from week to week and month to month. This temporal aspect presents an interesting challenge, not a barrier.

While our research was based on a preliminary survey, it does appear that New Zealand television does little to portray environment matters as important issues. Thus there is a clear gap that can be filled by informative, enabling and entertaining programmes about the state of the environment and sustainability. This is particularly so as 2005 marked the first year of the UNESCO Decade of Education for Sustainability (2005-2014). This is also an opportune time to broadcast, not only environmental programmes but also to show the links between the environment and lifestyles and the economy. 


\section{News}

This part of the study aimed to measure the type and frequency of content on network television prime-time news, and to assess the amount and type of coverage relating to the environment and sustainability.

\section{Method}

Four bulletins of 6pm television news were logged each week for three months, from September to November 2004 inclusive. In total, 45 bulletins were logged between 3 September and 29 November 2004. Twenty two were TVNZ One News bulletins and 23 were TV 3 bulletins. All were on separate dates, except on November 23 and 28, when the 6pm News was logged from both channels from $6 \mathrm{pm}$ to $7 \mathrm{pm}$, but not including the Sports segment. It is important to note that the survey did not include the network television $7 \mathrm{pm}$ news magazine programmes Close-Up (One) and Campbell Live (TV3).

The log listed each item within the news segment (ie. before the weather and sports news) with a brief description (eg 'Clinton receives heart operation', 'Interest rates to increase') and categorised items in 23 major categories. The category system was based on the systems of 'rounds' used in the newsroom of a typical metropolitan daily newspaper. ${ }^{1}$

\section{Findings}

Of the 663 items logged, 111 (16.7 percent) were classified as General News. This category was chosen when there was not a clear connection to any existing round, such as transport news or health news. Examples include: the return of the Unknown Soldier; the death of a prominent author; diplomacy between New Zealand and Israel; and an audit investigation within a local council.

The second-biggest category was Police/Emergency Services News (83 items, 12.5 percent) followed by World Conflict (63 items, 9.5 percent), and World News (47 items, 7.0 percent). Environment News ranked eighth out of 26 categories, with 26 items or 3.7 percent of the total. Figure 2 shows the items in each category.

\section{Discussion}

The selection of news items is not codified by rules. Instead, journalists make professional judgements about newsworthiness based on the editorial policy of the broadcaster or publisher, and by comparing the merits of each available story. While 'environment' news ranked in the top third by frequency, 


\section{Figure 2: Distribution of news items on NZ network TV news}

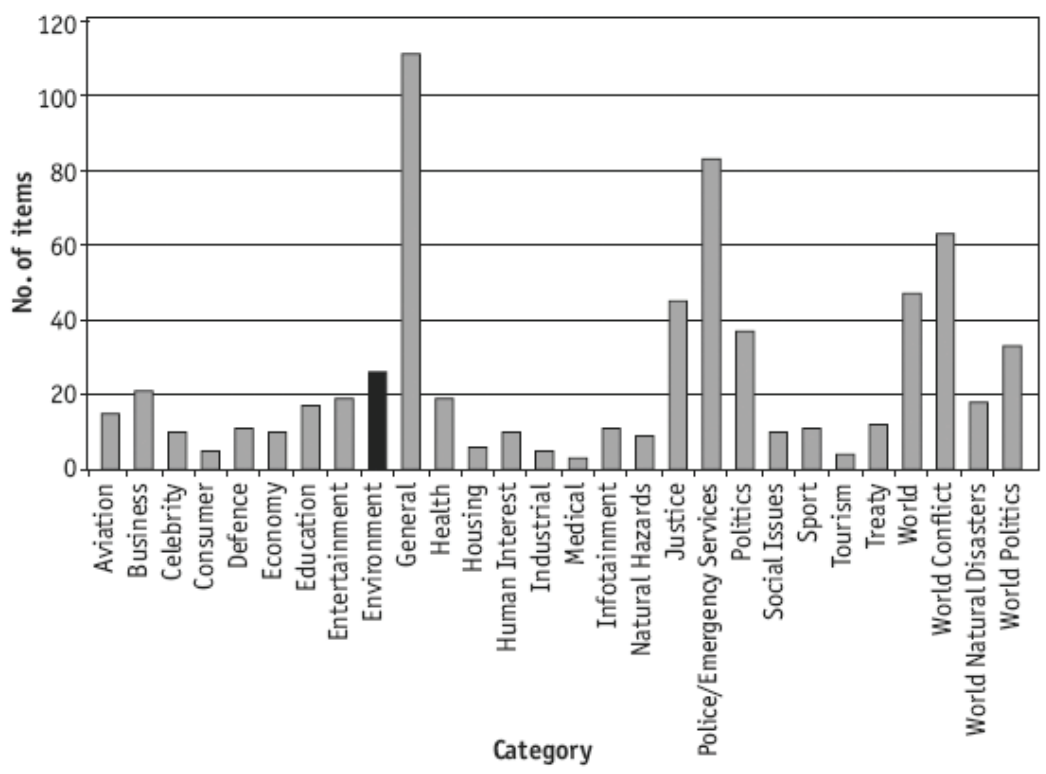

Note: The distribution is among the 26 categories listed over a three-month survey period, September-November 2004.

the proportion of the total items (3.7 percent) is low. It should be noted that this includes international environmental news items, and so the actual proportion of domestic environment news is less than 3.7 percent. The 26 items logged in the 'Environment' news category were:

1. Sand mining proposal, Mangawhai

2. Enforcement of fishing regulations

3. The review of the Resource Management Act

4. Annual return of godwits to Christchurch

5. Access dispute in the Greenstone Valley

6. Domestic coal ban in Southland

7. Conservation order on the Motueka River

8. Sand dredging proposal, Mangawhai

9. Tasmanian forestry plan

10. New stoat bait developed

11. Lodge proposed in sensitive area

12. $\mathrm{CO}_{2}$ policy in the UK

13. Cane toad population boom, Australia 
14. Stewart Island deer population increase

15. West Coast water quality problems

16. Antarctic iceberg nears Scott Base (TVNZ)

17. Yellow-eyed penguin deaths

18. Antarctic iceberg nears Scott Base (TV3)

19. Green Party's Christmas shopping tips

20. Dolphins killed in nets

21. Algae bloom, Southland

22. Urban native trees attacked, Auckland

23. Seawall controversy, Foxton (TVNZ)

24. Whale stranding, Bass Strait (TVNZ)

25. Seawall controversy, Foxton (TV3)

26. Whale stranding, Bass Strait (TV3)

Around a third of the items related to animal species, including whales, dolphins, deer, toads and stoats. There was also a predominance of items relating to marine and coastal environments. The survey suggests that environmental news reporting is quite narrow in its range. As well as being skewed towards conservation and species protection, there was no discussion of sustainability.

\section{Conclusions}

Television news is not reflecting the scientific effort or the body of public opinion which is being directed towards the environmental imperative or to improving the sustainability of human and ecological systems. The treatment and portrayal of 'the environment' is somewhat traditional and occasionally sensational. In terms of guidelines and requirements, it appears that the TVNZ news coverage falls below what is promised in the TVNZ Charter, which includes the requirement that TVNZ shall:

- 'seek to extend the range of ideas and experience available to New Zealanders' and that it will feature programming that

- 'contributes towards intellectual, scientific and cultural development, promotes informed and many-sided debate and stimulates critical thought, thereby enhancing opportunities for citizens to participate in community, national and international life.' (emphasis added).

The survey suggests there is a need to work with broadcasters to improve 
ECO-JOURNALISM AND SECURITY

knowledge and understanding of environmental issues, and its relationship to sustainability in particular, in order for an 'informed and many-sided debate' to occur.

\section{Advertisements}

For an environmentally responsible person, gauging advertisements is like gauging winds in a region. The worst events make the biggest impression, and bias one's sense of the prevailing flow. A survey of advertisements showed that most (about 85 percent) could be considered environmentally 'neutral', in the sense that while they encourage consumption (as of course most advertisements are designed to do just that), they encourage neither direct benefit nor direct damage to the environment. Only a small fraction of adverts were ranked as 'anti-environmental' - mainly vehicle advertisements. However some advertisements may be considered indirectly anti-environmental. Such advertisements promote and glamorise consumption (as so eloquently described by de Graaf et al., 2001) and irresponsible behaviour and or promote the 'rip into it' or 'party party' mentality, which can feed through to environmental damage.

\section{Some good news}

Advertising in NZ is regulated by the Advertising Standards Authority, which produces codes. A pleasing development has been the introduction of a 'Code for Advertising Vehicles', effective from 1 February 2005. This states the following.

\footnotetext{
Principle 3: Adverts portraying off-road driving should observe a due sense of responsibility to the environment.

Guidelines: Advertisements should not encourage environmental damage to areas of significant conservation value. These may include beaches, dunes, riverbeds, wetlands, tussock grasslands, lake margins and estuaries.
}

\section{General conclusions}

We believe that the media and journalists have a very important role to play in informing people about how to adopt good environmental practice. This belief is reflected in one of the principles of an ethical code that was ratified by the Asia-Pacific Forum of Environmental Journalists and other interna- 
tional environmental journalists' associations at the sixth World Congress of Environmental Journalists held in Colombo, Sri Lanka, in 1998. The second paragraph of that Code refers to the media as often being the only source of information on the environment and that the journalist's duty is to heighten the awareness by informing the public on environmental issues. Over the last few years, that Code appears to have been promulgated widely among forums of environmental journalists.

It appears to us that New Zealand national television is, in terms of programmes on sustainable development, both unbalanced and biased. There is an overall lack of programmes and news items about the state of the environment and about environmental sustainability. We suggest that New Zealand national television has a moral responsibility to address this bias and imbalance.

Internationally, there are examples of how the powerful 'orchestrational' influence of television can be used to positively promote environmentally or socially responsible behaviour (Brown, 2001). The Population Media Center (PMC, 2006) is an international organisation whose mission includes collaboration with the mass media, specifically to help stabilise population, and to reduce harmful environmental impacts.

Standards in television are regulated by the Code of Broadcasting Practice. The present Code covers eleven 11 'Standards', including:

- Good Taste and Decency

- Law and Order

- Fairness

- Children's Interests

- Violence

However the 'ethics' in no way extend to environmental care.

\section{Our proposals}

Television represents one of the strongest forces in society, with vast potential for building social cohesion and cooperation towards achievement of society's goals. Therefore we believe it is critical that television should play a much more proactive role in environmental responsibility. Specifically we propose the following:

1. Encourage New Zealand television broadcasters to:

a) reflect the community's widely held interest in environmental stew- 
ardship and sustainable development by;

b) avoiding negative counter-messages, eg. programmes or adverts which simply 'accept' or even trivialise irresponsible attitudes or behaviour towards our environment and its resources.

2. Add a 12th Standard to the Code of Broadcasting Practice, eg.

'Standard 12: Environmental Stewardship'

\section{Note}

1 The category for World News was divided into three subcategories. The 26 categories were: Aviation (frequency 15, ranking 14), Business (21, 9), Celebrity 10, 18), Consumer (5, 24=), Defence (11, 16=), Economy 10, 19), Education (17, 13), Entertainment $(19,10=)$, Environment $(26,8)$, General $(111,1)$, Health $(19,10=)$, Housing $(6,23)$, Human Interest $(10,20=)$, Industrial $(5,24=)$, 'Infotainment' $(3,26)$, Medical $(11,16=)$, Natural Hazards $(9,22)$, Justice $(45,5)$, Police/Emergency Services $(83,2)$, Politics $(37,6)$, Social Issues $(10,20=)$, Sport $(11,16=)$, Tourism $(4,25)$, Treaty $(12,15)$, World $(47,4)$, World Conflict $(63,3)$, World Natural Disaster $(18$, 12) and World Politics $(33,7)$.

\section{References}

Anonymous, (2003a). What does sustainable development mean for broadcasters? Intermedia, 31(2/3): pp. 5-7.

Anonymous (, 2003b). The coverage of sustainable development: challenges and opportunities. Intermedia, 31(2/3):, pp. 8-10.

Brown, L. (2001). Eco-economy: building an economy for the Earth, pp. 227-228. Earth Policy Institute. New York: W. W. Norton \& Co.

Chapman, G., Kumar, K., Fraser, C. and Gaber, I. (1997). Environmentalism and the mass media: the north-south divide. London and New York:, Routledge.

Gorney, C. (1992). Numbers versus pictures: did network television sensationalise Chernobyl coverage? Journalism Quarterly, 69: pp. 455-65.

de Graaf, J., Wann, D. and Naylor, T. H. (2001). Affluenza: the all-consuming epidemic. San Francisco:, Berrett-Koehler Publishers.

Hughey, K.F.D., G.N. Kerr and Cullen, R. (2004). Public perceptions of New Zealand's environment. Christchurch: EOS Ecology.

Musukuma, S. (2002). Putting environmental reporting on the news agenda. Intermedia, 30: pp. 16-17.

PMC (2006). Website of the Population Media Center. (Accessed August 2006.): www.populationmedia.org

Shanahan, J. and McComas, K. (1997). Television's portrayal of the environment: 1991-1995. Journalism and Mass Communication Quarterly, 74: pp. 147-59.

Shanahan, J. and McComas, K. (1999). Nature Stories: depictions of the environment and their effects. Cresskill, NJ: Hampton Press. 
Sims, M. (2002). The environment challenge. Intermedia, 30: pp. 30-37.

UN (2005). The millennium ecosystem assessment. New York: United Nations.

Professor Ian Spellerberg is director of the Isaac Centre for Nature Conservation at Lincoln University, New Zealand.

Dr Graeme Buchan is associate professor of environmental physics in Soil Sciences and Environmental Education at Lincoln University.

Nick Early is a former journalist, and the director of Restore New Zealand Ltd., a PR/communications company, based in Christchurch. An earlier version of this article was first presented at the Environment Institute of Australia and New Zealand Conference in Christchurch, 29 March-1 April 2005. Spelleri@Lincoln.ac.nz Buchan@Lincoln.ac.nz Nick@Restore.co.nz

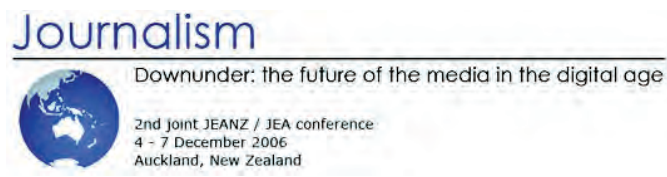

\section{Journalism Downunder}

The Journalism Education Association of New Zealand (JEANZ), with the support of AUT University's School of Communication Studies, is hosting the 2nd joint JEANZ/JEA conference in Auckland, New Zealand, December 4-7, 2006.

\section{KEYNOTE SPEAKER}

Roy Greenslade, professor of journalism at City University, London, since 2003, will be one of the keynote speakers at the conference. He is a leading commentator and columnist on the media, and is currently writing for the Daily Telegraph. As a journalist he rose to the highest levels of management in a career taking in The Sun, the London Sunday Times, and culminating in the editorship of the Daily Mirror.

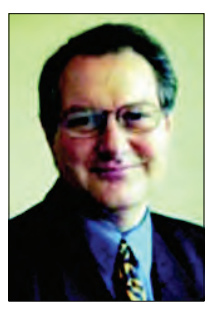

WEBSITE

http://artsweb.aut.ac.nz/journalism_conference/

Conference Comvenor: Allison Oosterman Email: aoosterm@aut.ac.nz 